\title{
Spectral and optical characterization of the new semi- organic crystal: 4-methylbenzylammonium chloride hemihydrate, to establish protonation and the effect of resultant hydrogen bonding
}

\author{
R AARTHI and C RAMACHANDRA RAJA* \\ Government Arts College (Autonomous), Kumbakonam 612002, India \\ *Author for correspondence (crrajaphy@ gmail.com)
}

MS received 6 November 2018; accepted 29 March 2019

\begin{abstract}
Methylbenzylammonium chloride hemihydrate (4MLBACH) single crystals were obtained by slowly evaporating the solvent. The characterization of the title crystal was first carried out and reported in this article. The crystal system and space group of the title crystal are identified as monoclinic and $C 2 / c$, respectively. The lattice parameter values were also calculated. Using Fourier transform infrared spectroscopy the protonation of 4-methylbenzylamine by hydrochloric acid and the formation of the crystal $4 \mathrm{MLBACH}$ were confirmed. The transmission window of the grown crystal is between 261 and $1100 \mathrm{~nm}$. The protonation of the amine group is confirmed by nuclear magnetic resonance spectral analysis. Z-Scan analysis was carried out to determine the nonlinear optical parameters. It reveals that the nonlinear susceptibility $\left(\chi^{3}\right)$ value is greater than some reported crystals. The title crystal exhibits saturable absorption and self-defocussing effects.
\end{abstract}

Keywords. 4-Methylbenzylammonium chloride hemihydrate; space group; protonation; molecular structure; third-order nonlinear susceptibility.

\section{Introduction}

Single crystals play a vital role in the field of nonlinear optics. Efforts are being made throughout the world to identify better nonlinear optical (NLO) crystals [1,2]. Even though organic crystals are dominant in controlling the phase transitions, polarization and frequency of light have received very little attention in terms of their mechanical and thermal properties $[3,4]$. On the other hand, inorganic materials attracted interest because they exhibit good second-harmonic generation efficiency along with these superior mechanical and thermal properties. While these inorganic ionic bonded crystals have high-melting point and chemical inertness they possess low NLO properties [5,6]. Obviously, the semi-organic crystals exhibit the properties of both crystals. These hybrid compounds show potential applications in linear and nonlinear optics [7-10]. Attempts have been made by several researchers, to synthesize and grow semiorganic crystals which may exhibit the properties of both organic and inorganic crystals.

The authors have identified a new semiorganic crystal '4-methylbenzylammonium chloride hemihydrate' (4ML$\mathrm{BACH}$ ) and its structure is reported by us [11]. This paper reports, the structural, spectral, linear and NLO properties of the title crystal. The structure of the crystal was dominated by the formation of a cationic hydrogen bond and anionic chloride interactions, which owes to a significant change in linear and nonlinear properties.

\section{Experimental}

\subsection{Materials and methods}

The crystal with the general formula $\mathrm{C}_{8} \mathrm{H}_{12} \mathrm{~N}^{+} \cdot \mathrm{Cl}^{-} \cdot 0.5 \mathrm{H}_{2} \mathrm{O}$ was synthesized by crystallization in solution at $37^{\circ} \mathrm{C}$ adopting a slow evaporation solution growth method. The chemical precursors 4-methylbenzylamine and hydrochloric acid are of 99.9\% purity (Sigma Aldrich). The growth of the crystal has been reported by the authors [11]. Good quality crystals of dimension $1 \times 1 \times 1 \mathrm{~mm}^{3}$ are obtained in a period of 15 days. The reaction scheme is given below.

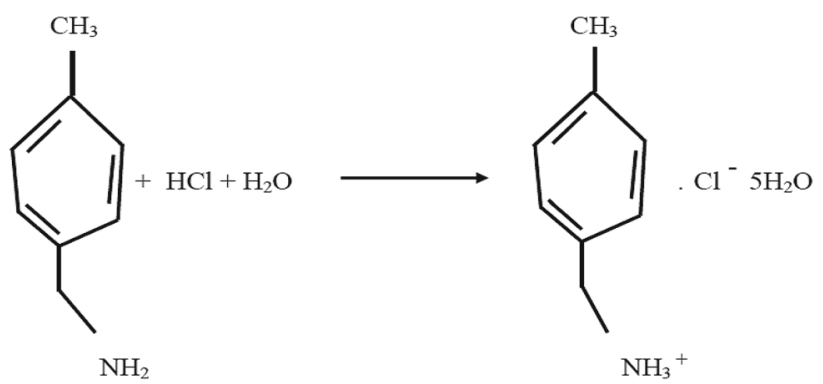

\section{Results and discussion}

\subsection{Single-crystal XRD analysis}

This study was conducted using a BRUKER NONIUS CAD4 diffractometer and radiation used is $\mathrm{MoK} \alpha$ with the 


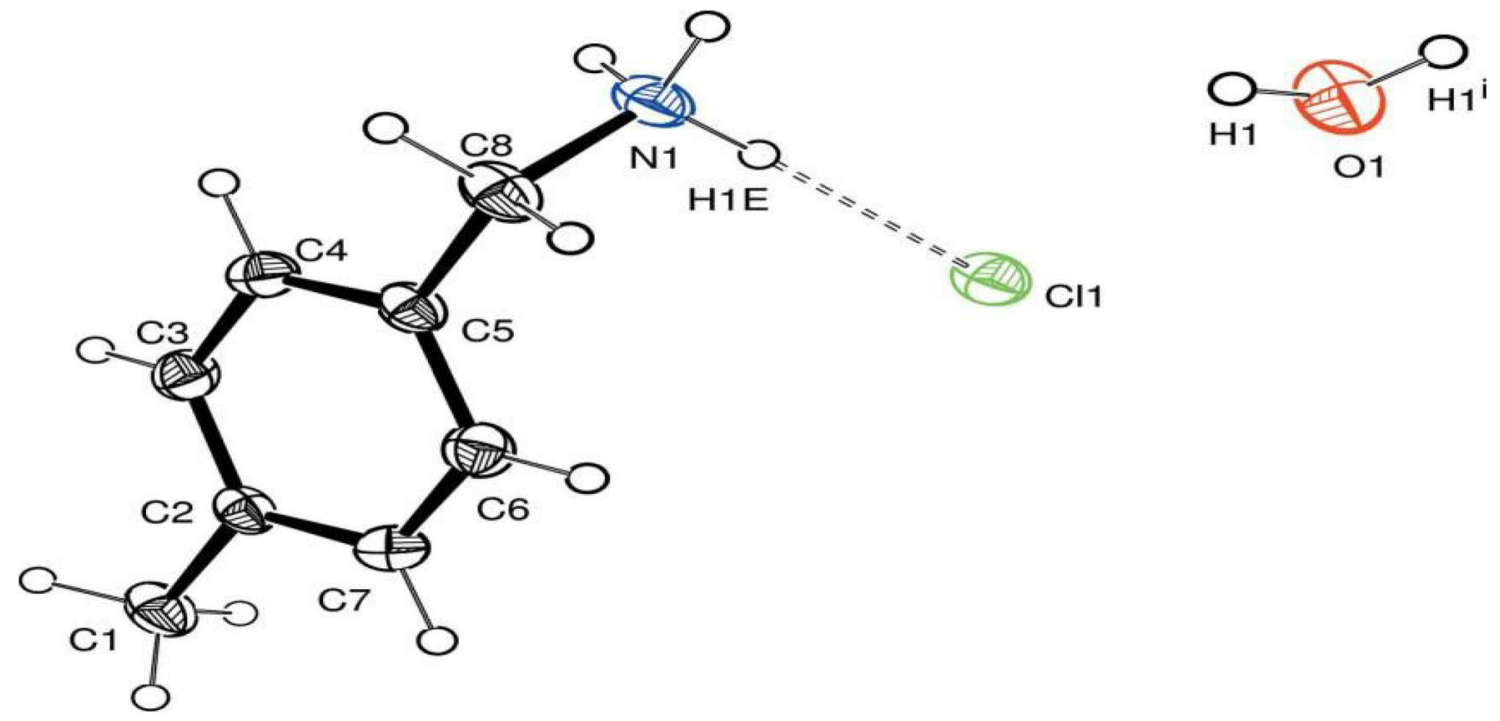

Figure 1. Molecular structure showing the protonated 4MLBACH [11].

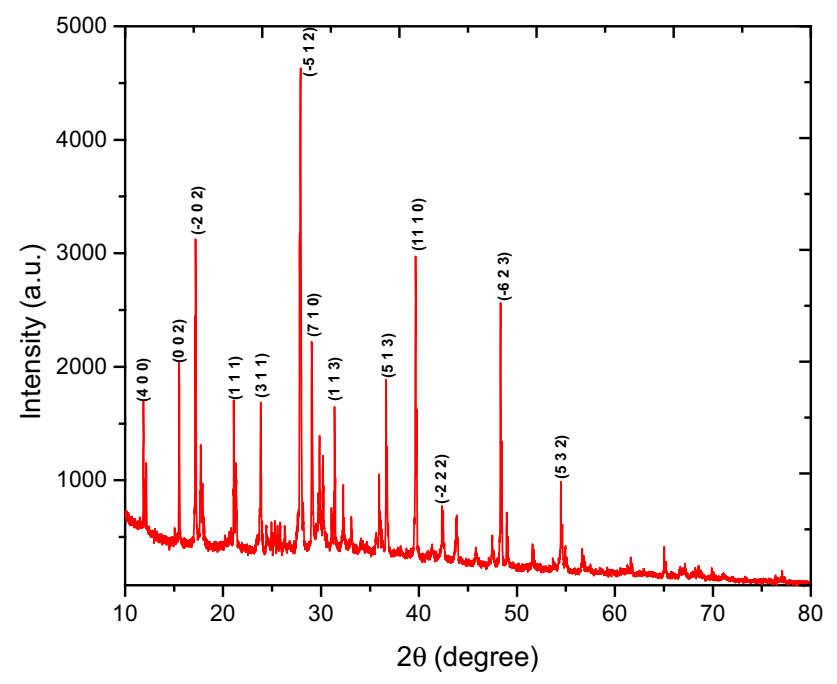

Figure 2. Powder XRD pattern of $4 \mathrm{MLBACH}$ crystals.

wavelength $\lambda=0.71069 \AA$. The structure of the title crystal is shown in figure 1 . The $\mathrm{X}$-ray diffraction (XRD) results reveal that 4MLBACH belongs to the monoclinic crystal system with the space group $C 2 / c$. The observed cell parameters are

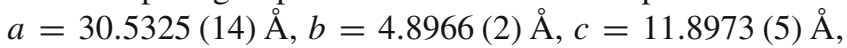
$\beta=99^{\circ} 067^{\prime}$ and volume $=1756.49(13) \mathrm{A}^{3}$.

\subsection{Powder XRD analysis}

The powder XRD pattern and diffraction indices of the crystal are shown in figure 2 . The crystallinity and cell parameters of 4MLBACH crystals have been studied from this analysis. The crushed powder sample was analysed using a Rich Seifert diffractometer with $\mathrm{CuK} \alpha(\lambda=1.54060 \AA)$ radiation. The sample is scanned for $2 \theta$ values from $10^{\circ}$ to $80^{\circ}$ at a

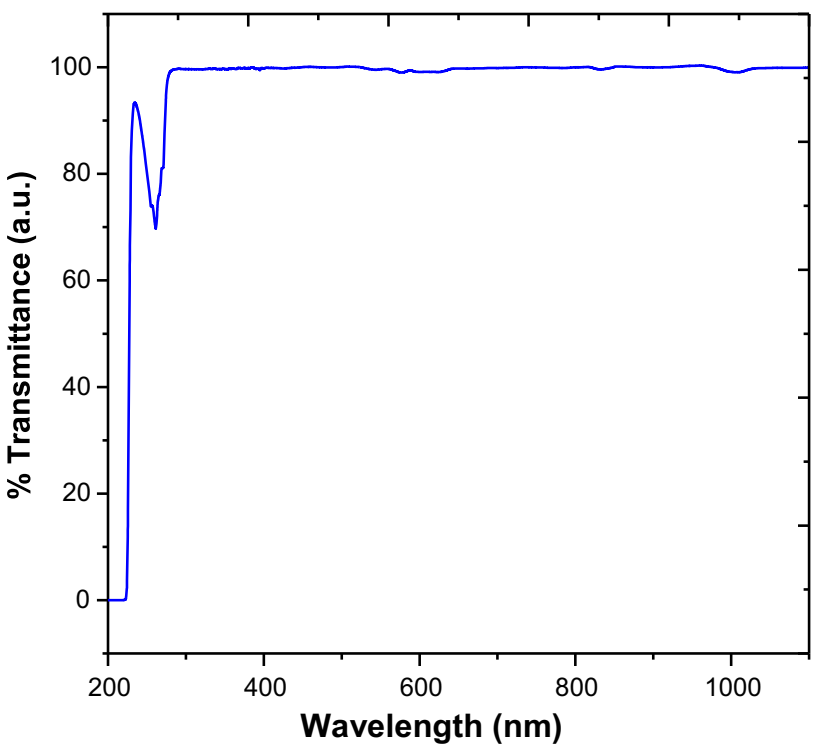

Figure 3. Optical transmission spectrum of 4MLBACH crystals.

rate of $2^{\circ} \mathrm{min}^{-1}$. Sharp peaks reveal the good crystallinity of $4 \mathrm{MLBACH}$. The diffraction pattern was indexed by the indx software package. The lattice parameter values were calculated by the Rietveld unit cell software package and were matched with single-crystal XRD data. The values, $a=$ $30.4915 \AA, b=4.9054 \AA, c=11.8255 \AA$ and $\beta=99^{\circ} 6337^{\prime}$ obtained from powder XRD analysis match well with singlecrystal XRD values [11].

\subsection{Transmission spectral study}

It is significant to find the optical transmittance window of the grown NLO crystals. The linear transmittance range of 


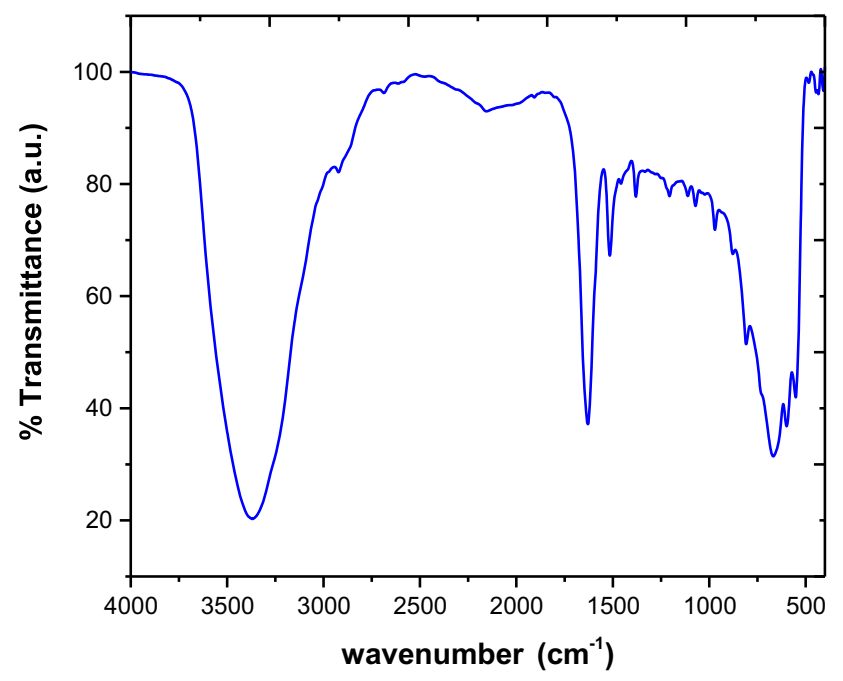

Figure 4. FTIR spectral pattern of 4MLBACH crystals.

4MLBACH crystals was measured in the range from 190 to $1100 \mathrm{~nm}$ using the Perkin-Elmer UV-Vis-NIR spectrophotometer. The 4MLBACH crystal sample is taken and mixed well with deionised water and kept in a cuvette. The transmission spectrum of $4 \mathrm{MLBACH}$ is presented in figure 3 . The lower cut-off wavelength of the title crystal is $260 \mathrm{~nm}$ and it is transparent up to the region tested. This reveals that the crystal can be used in optoelectronic applications [12]. A crystal has to be transparent for all the interacting wavelengths in NLO applications. Since the crystal is transparent from 260 to $1100 \mathrm{~nm}$ it can be used to generate all these wavelengths by frequency mixing processes. As the crystal is transparent for a Nd:YAG laser with a fundamental wavelength of $1064 \mathrm{~nm}$ and its third harmonic at $355 \mathrm{~nm}$, it can be used to generate the third harmonic generation [13].

\subsection{FTIR spectral analysis}

Fourier transform infrared (FTIR) spectroscopy is employed to find the presence of various functional groups present in the 4MLBACH crystal. A Perkin-Elmer FTIR spectrometer using a $\mathrm{KBr}$ pellet technique was used to record the spectrum in the range of $4000-400 \mathrm{~cm}^{-1}$ and the spectrum is shown in figure $4 . \mathrm{KBr}$ is used as a carrier for the sample in the IR spectrum and it is $100 \%$ optically transparent in the range of wavenumber $\left(4000-400 \mathrm{~cm}^{-1}\right)$. The spectrum clearly depicts the formation of 4-methylbenzylamine with hydrochloric acid through the protonation of $\mathrm{NH}_{2}$. The broad band observed at $3368 \mathrm{~cm}^{-1}$ which is attributed to the symmetric stretching vibrations of $\mathrm{NH}_{3}^{+}, \mathrm{C}-\mathrm{H}$ and $\mathrm{O}-\mathrm{H}$ groups which is the confirmation for the protonation of $\mathrm{NH}_{2}$ and also confirms the presence of $\mathrm{CH}$ and $\mathrm{OH}$ groups in the structure. The peak at $2922 \mathrm{~cm}^{-1}$ is due to the $\mathrm{CH}$ antisymmetric stretching vibration. For pure 4-methylbenzylamine the $\mathrm{CH}$ vibrations were observed between 2860 and $2921 \mathrm{~cm}^{-1}$. A small peak observed at $2687 \mathrm{~cm}^{-1}$ was attributed to the $\mathrm{H}-\mathrm{Cl}$

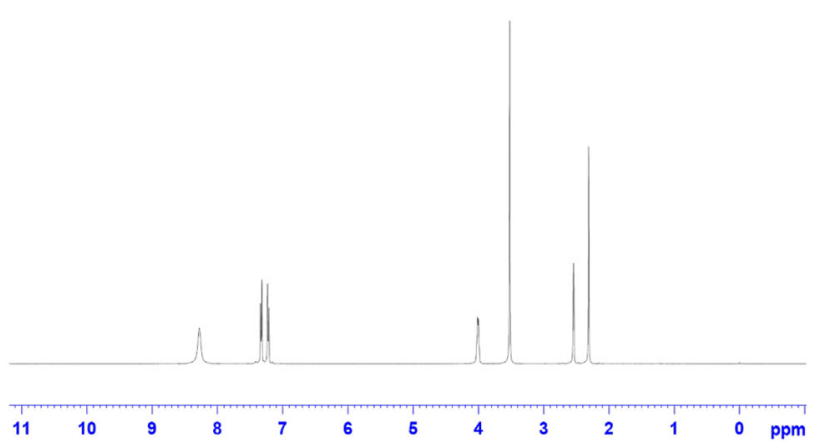

Figure 5. ${ }^{1} \mathrm{H}$ NMR chemical shifts (ppm) of 4MLBACH crystals.

vibration. A sharp peak at $1629 \mathrm{~cm}^{-1}$ is assigned to the $\mathrm{NH}_{3}^{+}$ symmetric bending mode. An absorption peak at $1515 \mathrm{~cm}^{-1}$ shows the vibration of $\mathrm{C}=\mathrm{C}$ aromatic stretching. The peak at $1457 \mathrm{~cm}^{-1}$ attributed to the $\mathrm{CH}_{2}$ bending vibration. The $\mathrm{CH}_{3}$ symmetric deformation mode of vibration is assigned to the peak at $1380 \mathrm{~cm}^{-1}$. The absorption band at $1206 \mathrm{~cm}^{-1}$ is attributed to $\mathrm{C}-\mathrm{C}$ bending vibrations. A peak observed at $1111 \mathrm{~cm}^{-1}$ is assigned to $\mathrm{CH}$ bending vibrations. A peak at $1071 \mathrm{~cm}^{-1}$ was attributed to the $\mathrm{C}-\mathrm{H}$ in plane deformation vibrational mode. The peak at $970 \mathrm{~cm}^{-1}$ belongs to the $\mathrm{C}-\mathrm{C}$ stretching mode of vibration. The $\mathrm{CH}_{2}$ rocking vibration was observed at $808 \mathrm{~cm}^{-1}$. A peak at $667 \mathrm{~cm}^{-1}$ owes to the $\mathrm{C}-\mathrm{H}$ out-of-plane deformation mode. The peak with low intensity was observed at $551 \mathrm{~cm}^{-1}$ which could be assigned to the vibrations of the benzene ring. The assignments are made by comparing the $4 \mathrm{MLBACH}$ spectrum with the literature [14-18].

\section{5 $\quad{ }^{1} H$ NMR spectral analysis}

A Bruker AMX spectrometer at $300 \mathrm{MHz}$ was used to record the ${ }^{1} \mathrm{H}$ nuclear magnetic resonance (NMR) spectrum of the title crystal using dimethyl sulphoxide as the solvent. The internal NMR reference is used as tetramethyl silane and the analysis was carried out at room temperature. Figure 5 shows the ${ }^{1} \mathrm{H}$ NMR profile of the title crystal. Table 1 shows its chemical shifts and assignments. The two observed peaks of the solvent clearly match well with the already reported value [19]. The spectrum showed that the 4MLBACH is coordinated with the chloride anion through the protonated $\mathrm{NH}_{3}^{+}$ group. For pure 4-methylbenzylamine, $\mathrm{NH}_{2}$ signals observed at $1.42 \mathrm{ppm}$ [20]. The same is shifted downfield and observed at $8.278 \mathrm{ppm}$ for the title crystal. The shift of the signal from lower ppm to higher ppm is due to the protonation of the $\mathrm{NH}_{2}$ group to $\mathrm{NH}_{3}^{+}$[21]. The shifts for methylene protons bonded to nitrogen was observed at 4.015 and $4.002 \mathrm{ppm}$ whereas, in the case of pure 4-methylbenzylamine the same was observed at $3.795 \mathrm{ppm}$. The difference observed in the chemical shift is $\Delta \delta=0.22 \mathrm{ppm}$ indicating the formation of $\mathrm{NH}_{3}$. The signal at $2.311 \mathrm{ppm}$ is attributed to the methyl group which established the presence of hydrogen in the aliphatic group. 
Table 1. ${ }^{1} \mathrm{H}$ NMR chemical shift values and assignments of 4MLBACH crystals.

\begin{tabular}{lccc}
\hline Atom & $\begin{array}{c}\text { Pure 4MLBA chemical } \\
\text { shift in ppm }(\delta)\end{array}$ & $\begin{array}{c}\text { 4MLBACH chemical } \\
\text { shift in ppm }(\delta)\end{array}$ & Assignments \\
\hline H4, H5, H6, H7 & $6-8$ & $7.213,7.223,7.320$ and 7.340 & $\mathrm{H}$ in aromatic ring \\
H8, H9 & 3.795 & $4.015,4.002$ & $\mathrm{CH}_{2}$ \\
H1, H2, H3 & 2.320 & 2.311 & $\mathrm{CH}_{3}$ \\
H10, H11, H12 & 1.42 & 8.278 & $\mathrm{NH}_{3}$ \\
\hline
\end{tabular}

The aromatic ring hydrogen signal is found as a multiplet between 7.213 and $7.340 \mathrm{ppm}$. The position of the hydrogen atom in the structure of the molecule is represented in figure 6.

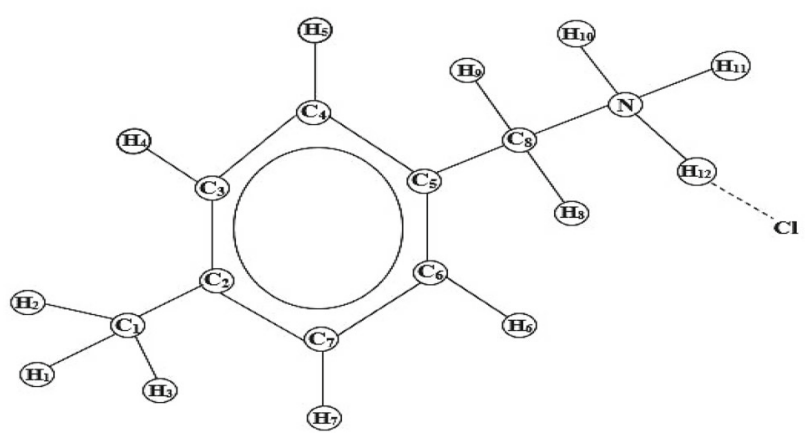

Figure 6. Structure of $4 \mathrm{MLBACH}$ representing the position of carbon and hydrogen atoms.

\section{6 ${ }^{13}$ C NMR spectral analysis}

The ${ }^{13} \mathrm{C}$ NMR profile is depicted in figure 7. The chemical shifts and the assignments for the different carbon atoms are presented in table 2. The aromatic carbon attached to the methylene group shows a sharp peak at $138.31 \mathrm{ppm}$. The peaks observed at $129.25,129.62$ and $131.36 \mathrm{ppm}$ were due to the other $\mathrm{C}$ atoms attached to the ring [22]. The signal at $42.60 \mathrm{ppm}$ is due to the $\mathrm{CH}_{2}$ group bonded with $\mathrm{NH}_{3}$. In the case of pure 4-methylbenzylamine the $\mathrm{CH}_{2}$ peak is present at $46.21 \mathrm{ppm}$. The coordination of $\mathrm{H}^{+}$cations and $\mathrm{Cl}^{-}$anions with 4-methylbenzylamine was confirmed by this peak at $42.60 \mathrm{ppm}$ which in turn establishes the $\mathrm{N}-\mathrm{H} \cdots \mathrm{Cl}$ interaction. The signal for carbon present in the methyl group peak is observed at $21.18 \mathrm{ppm}$.

\subsection{Z-Scan analysis}

Sheik Bahae et al [23] introduced and employed a Zscan analysis method to determine the nonlinear refractive
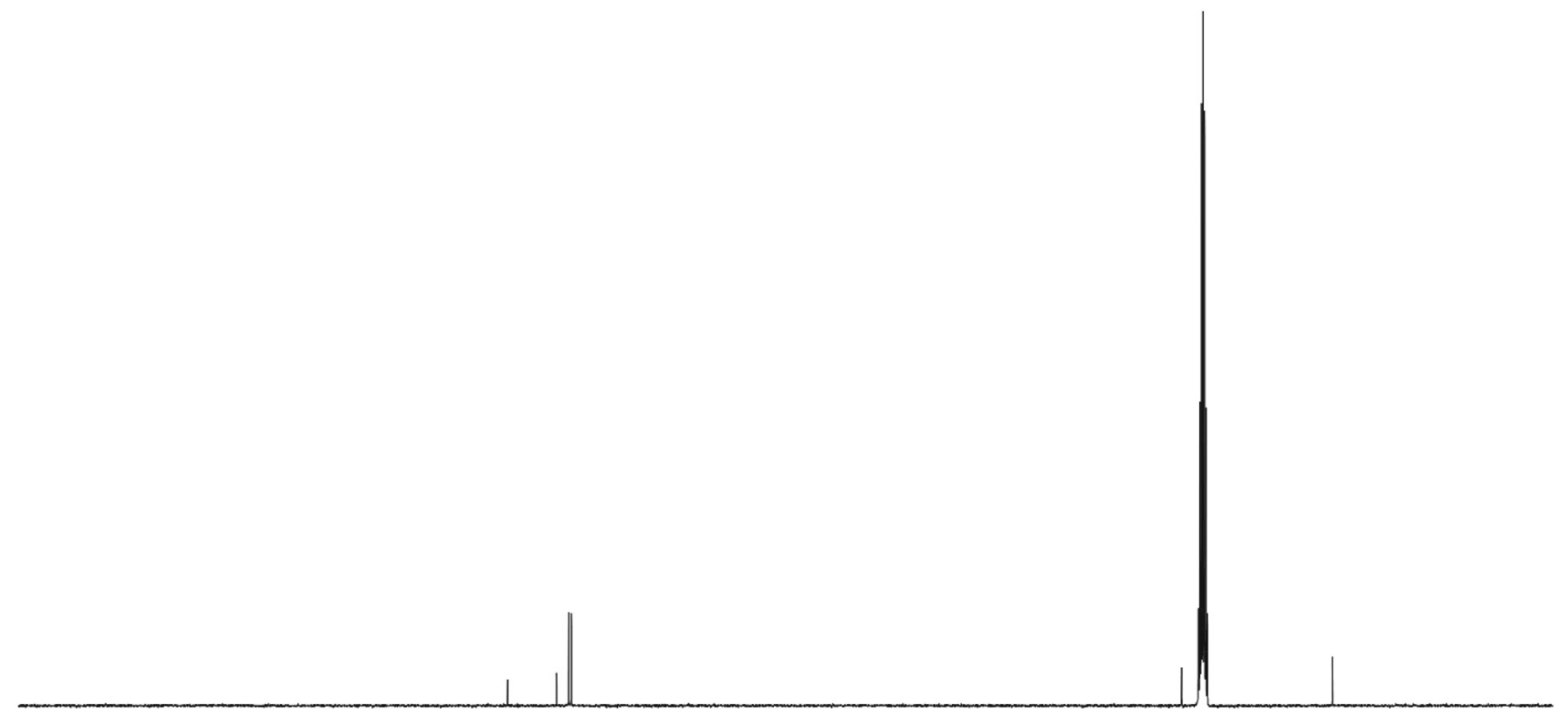

$\begin{array}{lllllllllll}200 & 190 & 180 & 170 & 160 & 150 & 140 & 130 & 120 & 110 & 100\end{array}$

Figure 7. ${ }^{13} \mathrm{C}$ NMR chemical shifts (ppm) of $4 \mathrm{MLBACH}$ crystals. 
Table 2. ${ }^{13} \mathrm{C}$ NMR chemical shift values and assignments of $4 \mathrm{MLBACH}$ crystals.

\begin{tabular}{lccc}
\hline Atom & Pure 4MLBA chemical shift in ppm $(\delta)$ & 4MLBACH chemical shift in ppm $(\delta)$ & Assignments \\
\hline C1 & 20.97 & 21.18 & $\mathrm{CH}_{3}$ \\
C2 & 140.47 & 138.31 & $\mathrm{CH}$ \\
C3 & 129.10 & 129.62 & $\mathrm{CH}$ \\
C4 & 136.09 & 131.36 & $\mathrm{CH}$ \\
C5 & 126.95 & 129.25 & $\mathrm{CH}$ \\
C6 & 136.09 & 131.36 & $\mathrm{CH}$ \\
C7 & 129.10 & 129.62 & $\mathrm{CH}$ \\
C8 & 46.21 & 42.60 & $\mathrm{CH}_{2}$ \\
\hline
\end{tabular}
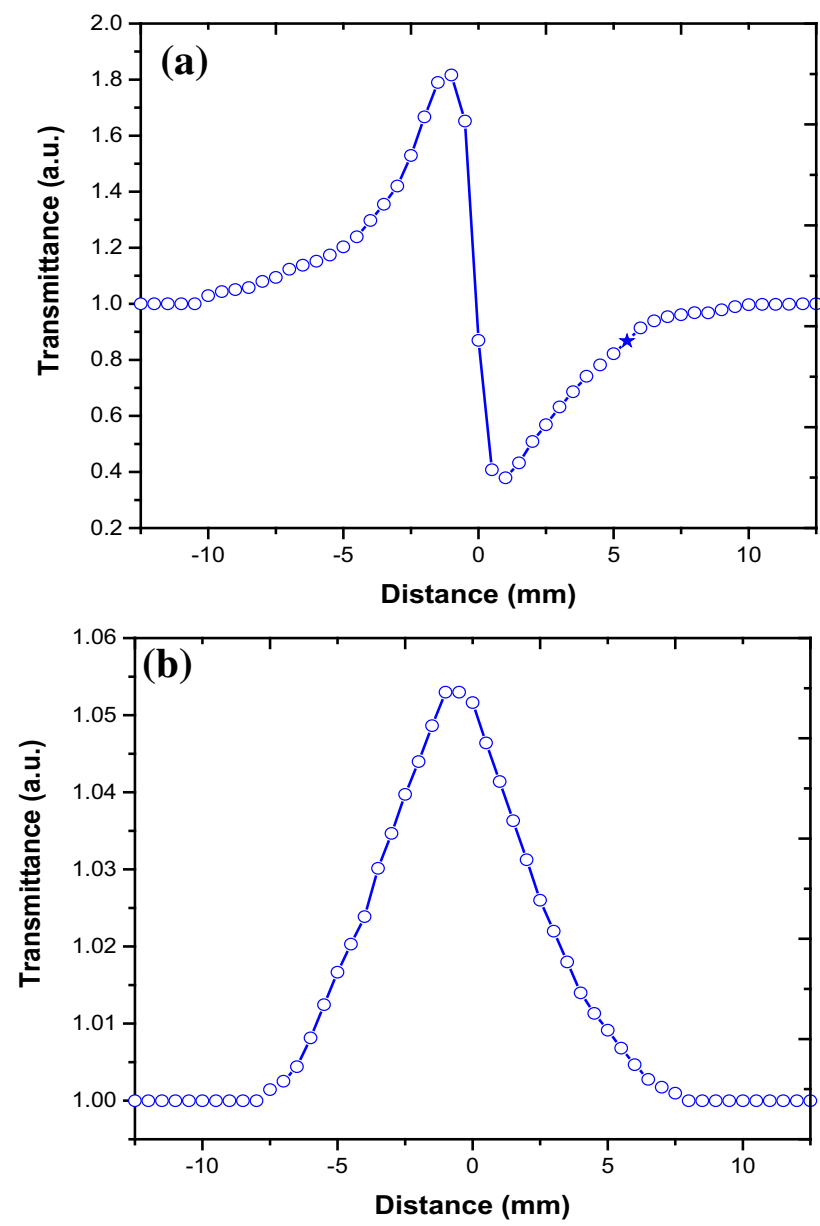

Figure 8. (a) Z-Scan closed aperture trace of $4 \mathrm{MLBACH}$ crystals. (b) Z-Scan open aperture trace of $4 \mathrm{MLBACH}$ crystals. index $\left(n_{2}\right)$, absorption coefficient $(\beta)$ and third-order NLO susceptibility $\left(\chi^{3}\right)$.

This study was carried out for the 4MLBACH crystals using a single-beam $\mathrm{Z}$-scan technique equipped with a $\mathrm{Nd}-\mathrm{YAG}$ laser with an intensity of $5 \mathrm{~mW}(\lambda=532 \mathrm{~nm})$, focussed by a lens with a focal length of $3.5 \mathrm{~cm}$. This method is a usual and simple method to determine the NLO parameters such as the refractive index $\left(n_{2}\right)$, absorption coefficient $(\beta)$ and thirdorder NLO susceptibility $\left(\chi^{3}\right)$ by closed and open aperture mode very accurately using the formula reported in the literature [24]. Measurements of the closed aperture and the open aperture as a function of the sample position $Z$ have been performed for the 4MLBACH crystal and illustrated in figure $8 \mathrm{a}$ and $\mathrm{b}$, respectively. The pre-focal peak followed by the post-focal valley nature of the closed aperture curve enunciates that the crystal is pronounced to negative $n_{2}$ which is due to the occurrence of the self-defocussing effect. The negative nonlinearity contributes to high-laser damage threshold [25]. This finds application in optical sensors like night vision devices [26]. The open aperture $Z$-scan curve suggests that the sample exhibits the larger transmission near the focus $(Z=0)$ which is due to the saturable absorption of the 4MLBACH crystal [24]. The primary applications of saturable absorption are $\mathrm{Q}$ switching of lasers that generate short optical pulses, passive mode locking to obtain ultrashort pulses and optical bistability applied in optical memory, optical transistor, optical switching and also useful for cleaning up pulse shapes [27-30]. The value of third-order NLO susceptibility $\chi^{3}$ of the crystal was found to be $3.57 \times 10^{-6}$ esu (table 3 ). The crystal structure is constructed by $\mathrm{N}-\mathrm{H} \cdots \mathrm{Cl}$ and $\mathrm{C}-\mathrm{H} \cdots \mathrm{Cl}$ interactions which results in the formation of hydrogen bonds as reported by the authors [11]. These hydrogen bonds change the electronic distribution and enhance the

Table 3. Third-order NLO parameters of 4MLBACH crystals.

\begin{tabular}{ll} 
Nonlinear refractive index $\left(n_{2}\right)$ & $7.02 \times 10^{-8} \mathrm{~cm}^{2} \mathrm{~W}^{-1}$ \\
Nonlinear absorption coefficient $(\beta)$ & $0.04 \times 10^{-4} \mathrm{~cm} \mathrm{~W}^{-1}$ \\
Real part of third-order susceptibility $\left[\operatorname{Re}\left(\chi^{3}\right)\right]$ & $3.56 \times 10^{-6} \mathrm{esu}$ \\
Imaginary part of third-order susceptibility $\left[\operatorname{Im}\left(\chi^{3}\right)\right]$ & $0.24 \times 10^{-6} \mathrm{esu}$ \\
Third-order nonlinear susceptibility $\left(\chi^{3}\right)$ & $3.57 \times 10^{-6} \mathrm{esu}$ \\
\hline
\end{tabular}


Table 4. Comparison of the $\chi^{3}$ value of $4 \mathrm{MLBACH}$ with some third-order NLO crystals.

\begin{tabular}{lcc}
\hline Name of the crystal & Third-order optical susceptibility $\left(\chi^{3}\right)(\mathrm{esu})$ & Reference \\
\hline 4MLBACH & $3.57 \times 10^{-6}$ & Present work \\
VMST & $9.6963 \times 10^{-12}$ & {$[33]$} \\
MMST & $2.29 \times 10^{-7}$ & {$[34]$} \\
KDNB & $3.02 \times 10^{-8}$ & {$[35]$} \\
\hline
\end{tabular}

molecular polarization. This could be the reason for the large third-order susceptibility exhibited by the title crystal [31,32]. The $\chi^{3}$ value of 4MLBACH was compared with the values of some reported NLO crystals and are presented in table 4.

\section{Conclusions}

The title crystal was grown using a solvent evaporation technique. The colourless good quality crystals were harvested in 15 days. They crystallize in the monoclinic crystal system with the $C 2 / c$ space group. The wide transparency width of the title crystal was ascertained by the transmission spectrum. Vibrational spectroscopy was employed to analyse the functional group of 4MLBACH single crystals. The protonated molecular structure is once again confirmed by ${ }^{1} \mathrm{H}$ and ${ }^{13} \mathrm{C}$ NMR spectroscopy. It is found that the hydrogen bond is responsible for the larger third-order susceptibility values.

\section{Acknowledgements}

The authors acknowledge the scientific supports extended by sophisticated analytical instruments facility (SAIF), Indian Institute of Technology (IITM), Chennai for providing singlecrystal XRD, gratefully acknowledge the Instrumentation centre of St Joseph's College, Trichy for recording UV-VisNIR and FTIR spectra and for NMR spectrum, Gandhigram Rural Institute. The authors also gratefully thank Dr G Vinitha, VIT, Chennai for providing third-order nonlinear testing facility for recording Z-scan measurement.

\section{References}

[1] Ruiz B, Yang Z, Gramlich V, Jazbinsek M and Gunter P 2006 J. Mater. Chem. 162839

[2] Suresh S and Arivouli D 2011 J. Optoelectron. Biomed. Mater. 363

[3] Ferguson B and Zhang X C 2002 Nat. Mater. 126

[4] Bordui P F and Fejer M M 1993 Annu. Rev. Mater. Sci. 23321

[5] Kubodera K and Kobayashi H 1990 Mol. Cryst. Liq. Cryst. 182 103

[6] Jiang M H and Fang Q 1999 Adv. Mater. 111147

[7] Kimizuka N and Kunitake T 1996 Adv. Mater. 889

[8] Mitzi D B, Chondroudis K and Kagan C R 2001 IBM J. Res. Dev. 4529
[9] Santos S N C, Almeida J M P, Paula K T, Tomazio N B, Mastelaro V R and Mendonça C R 2017 Opt. Mater. 73 16

[10] Karthick N, Sankar R, Jayavel R and Pandi S 2009 J. Cryst. Growth 312114

[11] Aarthi R, Thiruvalluvar A and Ramachandra Raja C 2017 IUCrData 2 x 1712

[12] Bharath D and Kalainathan S 2014 Spectrochim. Acta. A 120 32

[13] Natarajan S, Shanmugam G and Martin Britto Dhas S A 2008 Cryst. Res. Technol. 43561

[14] Barth A 2000 Prog. Biophys. Mol. Biol. 74141

[15] Brittain H G 2011 Cryst. Growth Des. 112500

[16] Grayson M 2003 Internet Electron. J. Mol. Des. 2

[17] Brittain H G 2009 Cryst. Growth Des. 93497

[18] Gunasekaran S, Sailatha E, Seshadri S and Kumaresan S 2009 Indian J. Pure Appl. Phys. 4712

[19] Karthigha S, Kalainathan S, Hamada F, Yamada M and Kondo Y 2016 RSC Adv. 633159

[20] https://sdbs.db.aist.go.jp/sdbs/cgi-bin/direct_frame_top.cgi

[21] Beecher C N and Larive C K 2015 Anal. Chem. 879842

[22] Kefi R, Jeanneau E, Lefebvre F and Nasr C B 2011 Acta Cryst. C67 m126

[23] Sheik-Bahae M, Said A A, Wei T H, Hagan D J and Van Stryland E W 1990 IEEE J. Quantum Electron 26760

[24] Sangeetha P, Jayaprakash P, Nageshwari M, Rathika Thaya Kumari C, Sudha S, Prakash M et al 2017 Physica B 525 164

[25] Gupte S S, Marcano O A, Pradhan R D, Desai C F and Melikechi N 2001 J. Appl. Phys. 894939

[26] Zhou Y S, Wang E B and Peng J 1999 Polyhedron 181419

[27] Fan H-L, Ren Q, Wang X-Q, Li T-B, Sun J, Zhang G-H et al 2009 Nat. Sci. 1136

[28] Nihei H and Okamoto A 2001 Proc. SPIE 4416470

[29] Assanto G, Wang Z, Hagan D J and Vanstryland E W 1995 Appl. Phys. Lett. 672120

[30] Mazurenko D A, Kerst R, Dijkhuis J I, Akimov A V, Golubev V G, Kurdyukov D A et al 2003 Phys. Rev. Lett. 91213903

[31] Lei C, Yang Z, Zhang B, Lee M-H, Jing Q, Chen Z et al 2014 Phys. Chem. 1620089

[32] Gomathi R, Madeswaran S and Rajan Babu D 2017 J. Mater. Sci.: Mater. Electron 2811374

[33] Krishna Kumar M, Sudhahar S, Pandi P, Bhagavannarayana G and Mohan Kumar R 2014 Opt. Mater. 36988

[34] Kumar M K, Sudhahar S, Silambarasan A, Sornamurthy B M and Kumar R M 2014 Optik 125751

[35] Karuppasamy P, Sivasubramani V, Senthil Pandian M and Ramasamy P 2016 RSC Adv. 6109105 